\title{
The Impact of Cosmetic Plastic Surgery on Body Image and Psychological Well-Being: A Preliminary Study
}

\author{
Valentina Elisabetta Di Mattei ${ }^{1,2^{*}}$, Elena Pagani Bagliacca ${ }^{1}$, Alessandro Ambrosi $^{2}$, Luciano Lanfranchi ${ }^{3}$, Franz Baruffaldi \\ Preis $^{3}$ and Lucio Sarno ${ }^{1,2}$ \\ ${ }^{1}$ Clinical and Health Psychology Unit, San Raffaele Hospital, Milan, Italy \\ ${ }^{2}$ Faculty of Psychology, University Vita-Salute San Raffaele Milan, Italy \\ ${ }^{3}$ Plastic Surgery Department, Galeazzi Orthopaedic Institute, I.R.C.C.S., and San Raffaele Hospital - Milan, Italy
}

\begin{abstract}
Background: The relationship between body image and cosmetic surgery represents a new generation of research on the psychological aspects of cosmetic surgery.

Objective: This preliminary study intends to investigate the role of distress relating to body image in conditioning the levels of post-operatory patient benefit both the impact of cosmetic surgery on the state of psychological well-being and body image through the analysis of the differences between the pre and post-operative stages.

Methods: The study lasted 12 months and it occurred in two stages, a pre-operative stage $(\mathrm{N}=85)$ and a post-operative stage $(\mathrm{N}=85)$. The patients, subjected to different aesthetic operations, were administered the Body Uneasiness Test, Psychological General Well-Being Index - Short version in both the stages and the Glasgow Benefit Inventory in the post-operative phase.

Results: The post-operative patient benefit was conditioned by the existence of clinically significant distress related to body image in the pre-operative stage, in accordance with the degree of severity; the operation had a positive impact on both the state of distress linked to psychological well-being and that relating to body image but, in the latter case, the improvement of distress depends on severity; all the patients with a body image disorder in the pre-operative stage continued to show this even after 12 months.

Conclusions: A careful assessment of body image and its disorders in the stage before the operation may allow the identification of patients who may be dissatisfied by the outcome of the operation.
\end{abstract}

\section{Introduction}

In 2012, over ten million strictly surgical and cosmetic medicine operations were performed in the USA [1], with an increase of $250 \%$ since 1997. The growing acceptance of aesthetic plastic surgery operations has been attributed to a series of factors; in particular, in recent years, researchers have identified a series of intrapsychic and social factors [2] which determine the desire and, at times, the undiscriminating acceptance of resorting to cosmetic procedures. The main factor motivating people to undergo cosmetic operations, emerging from the results of numerous studies, is dissatisfaction with body image [2-5] defined as "a set of perceptions, affections and ideas that an individual attributes to their body through their personal history and the attitudes of the general public" [6]. However, it is essential to differentiate between a slight dissatisfaction with one's appearance (which usually concerns a personal feeling of dissatisfaction that does not reach pathological levels, [7-9]) and the excessive concern that causes a clinically significant uneasiness [10] or a Body Image Disorder [9,11] for the individual. This excessive concern is not only frequently met in the sphere of plastic surgery $[5,12]$ but also conditions the post-operative satisfaction of patients $[13,14]$, which is the fundamental indicator of the success of an aesthetic plastic surgery operation [15-17]. It is important to identify and diagnose patients affected by these disorders in a cosmetic surgery sphere as the operation, in this case would be of little use if not even counterproductive [18].

Some studies have looked at the degree of body image dissatisfaction among individuals who present for aesthetic procedures. A number of studies have found increased body image dissatisfaction among patients who present for cosmetic procedures, as compared with population norms or individuals not interested in surgery [10,19-21]. In several studies, this dissatisfaction appeared to be focused on the feature for which the individual sought surgery, instead of overall body image. A number of studies have documented improvements in body image following aesthetic treatments [22-5]. In a recent study of the psychosocial outcomes 5 years after cosmetic surgery, von Soest and colleagues [23] found that patients experienced greater satisfaction with their general appearance as well as with the specific body area altered by treatment. It has also been shown that a positive change in the physical aspect leads to an improvement in psychological wellbeing $[26,27]$. However, from the research carried out, it is premature to conclude that operations and aesthetic correction procedures lead to psychological benefits (reduction of anxiety, depression, etc.) in most patients [12]. The relationships between body image and cosmetic operations have been at the centre of empirical studies only in the last decade; according to Sarwer and Crerand [12], this is the new generation of research on the psychological aspects of aesthetic plastic surgery, as the main aim of any type of cosmetic surgery is to facilitate the psycho-social functioning of the patient by changing their body image [28].

"Corresponding Author: Valentina Elisabetta Di Mattei, Clinical and Health Psychology Unit, San Raffaele Hospital, Milan, Italy, Tel: +3902291751551; Fax: +390291971454; E-mail: dimattei.valentina@hsr.it

Citation: Di Mattei VE, Pagani Bagliacca E, Ambrosi A, Lanfranchi L, Baruffaldi Preis F, et al. (2015) The Impact of Cosmetic Plastic Surgery on Body Image and Psychological Well-Being: A Preliminary Study. Int J Psychol Behav Anal 1: 103. doi: http://dx.doi.org/10.15344/2455-3867/2015/103

Copyright: (c) 2015 Di Mattei et al. This is an open-access article distributed under the terms of the Creative Commons Attribution License, which permits unrestricted use, distribution, and reproduction in any medium, provided the original author and source are credited. 
Citation: Di Mattei VE, Pagani Bagliacca E, Ambrosi A, Lanfranchi L, Baruffaldi Preis F, et al. (2015) The Impact of Cosmetic Plastic Surgery on Body Image and Psychological Well-Being: A Preliminary Study. Int J Psychol Behav Anal 1: 103. doi: http://dx.doi.org/10.15344/2455-3867/2015/103

Page 2 of 6

Body image can be described as the way in which the individual experiences and considers his body, a model to which all affectivecognitive type elements linked to the body can be traced [29]. Therefore, it is a complex multi-dimensional construct that includes perceptive, affective and cognitive components of the bodily experience [30]. Research carried out to date has mainly taken body dissatisfaction into consideration (a cardinal symptom and most relevant risk factor of the Body Dysmorphic Disorder and Eating Disorders [30-32]), which, nevertheless, is not in itself a sufficiently specific indicator of Body Image Disorder [7-9].

This preliminary study intends: 1) to assess in the preoperative stage whether the existence of Body Image Disorder (clinically significant uneasiness relating to body image) influences the post-operative satisfaction; 2) to study the impact of aesthetic plastic surgery on body image and its pathologies through the analysis of the differences between the pre $\left(t_{0}\right)$ and post-operative $\left(t_{1}\right)$ stages; 3$)$ to study the impact of resorting to aesthetic plastic surgery operations on the state of well-being/uneasiness linked to the emotional and affective sphere (psychological well-being) through the analysis of the differences between the pre $\left(\mathrm{t}_{0}\right)$ and post-operative $\left(\mathrm{t}_{1}\right)$ stages.

\section{Materials and Methods}

\section{Individuals}

Candidates for aesthetic plastic surgery were selected from the Reconstructive and Aesthetic Plastic Surgery Operational Unit which was the source of data collection. The sample consisted of patients recruited in two main Hospitals of Milan. The study was carried out at two separate times: a pre-operative stage and a post-operative one. To be included in this study, the patients must have to present any of the following criteria: a) be more than 18 years old, b) be Caucasian, c) Italian speaking and d) have a time interval between the pre and post-operative stages of 12 months. These criteria were adopted both for legal reasons (see the disclaimer for individuals of less than 18 years of age) and to limit possible cultural bias due to the incorrect understanding of the protocol used in the study.

Before the questionnaires were given directly to the participants, all the patients were informed of the aims of the research, ensuring the anonymity of the data and asking them to sign the consent to participation and be re-contacted at a distance of at least one year from the operation to complete additional questionnaires.

A total of 85 people were recruited, 77 of them were female (90.6\%), while the remaining 8 were male $(9.4 \%)$. The individuals underwent three different types of aesthetic plastic surgery operations: 28 (32.9\%) rhinoplasty operations, 32 mastoplasty (of whom the, $24.7 \%$, had breast augmentation and the $12.9 \%$ a breast reduction), and the remaining 25 individuals $(29.4 \%)$ underwent operations for the correction of body volume (10.6\%) had abdominoplasty and the remaining $18.8 \%$ had liposuction of thighs, hips, legs or buttocks). The age of the patients varies from 18 to 57 with an average of 32.50 $(\mathrm{SD}=8.58)$.

According to 2012 statistics [1], 90.5\% of cosmetic surgeries were performed on female patients, and the remaining $9.5 \%$ on male patients, reflecting the disparity found in this research.

The second part of the study (post-operative stage) was carried out around one year after the operation.
The patients completed and sent the self-administered questionnaires (created in a protected format) electronically. The anonymity of the responses was guaranteed by aggregating the data and thus removing the identity of each respondent from the data pool (in accordance with the guidelines of the Research Code of Ethics in Psychology - AIP).

\section{Materials}

All the patients completed the following tests in the pre-operative stage. The Body Uneasiness Test (BUT) was used for the study on body image and its pathologies [33-35]. This is a self-administered, multi-dimensional Italian test for the clinical assessment of uneasiness relating to body image. It is a valuable tool for the screening and the clinical assessment of abnormal body image attitudes, the psychometrical characteristics are confirmed [33]. The test consists in 71 items with multiple choice answers and it is divided into two parts. The first part (BUT A) consists of 34 clinical items while the second (BUT B) of 37 items that list parts and functions of the body. The individual is invited to answer how much each of the clinical items (BUT A) corresponds to their current situation (E.g. "I spend a lot of time in front of the mirror") and how much they detest the listed parts and functions of the body (BUT B -E.g. the shape of my head; nose; legs-). The items are assessed on a scale of six points from 0 (never) to 5 (always); the higher scores indicate greater severity. Five factors were isolated through the factor analysis: Weight Phobia (WP, Cronbach's $\alpha=0.85$ ), Body Image Concerns (BIC; Cronbach's $\alpha=0.92$ ), Avoidance (A, Cronbach's $\alpha=0.75$ ), Compulsive SelfMonitoring (CSM, Cronbach's $\alpha=0.81$ ) and Depersonalisation (D, Cronbach's $\alpha=0.77$ ). Various measures can be obtained, including the Global Severity Index (GSI), or overall average score, by summing the scores from the clinical scale (BUT A) and dividing them by the number of items (34). In the assessment of the BUT clinical scale, the existence of clinically significant uneasiness in relation to body image is improbable if the GSI score is $<1.2$ and probable if that score is $\geq$ 1.2 [36].

The PGWB-S, Psychological General Well-Being Index-Short version [37] was used. This instrument provides an index that measures the self-representation of the well-being/uneasiness linked to the emotional and affective sphere for the assessment of psychological well-being. In this study, the Italian adaptation of the reduced version [37] consisting in 6 items was used; the short version (PGWB-S; Cronbach's $\alpha=0.90$ ) gives a global score (between 0 - worst possible state - and 30 - best possible state -) which predicts $93 \%$ of the variance of the total score of the extended version [37]. The global score assesses the following dimensions of psychological well-being: anxiety, depression, positivity and well-being, self-control, general state of health, and vitality.

In the follow-up stage, in addition to the questionnaires mentioned above, the patients completed the Glasgow Benefit Inventory [38]. A post-intervention questionnaire which assesses the interventions effects on the health status of patients. For this measure, the definition of health status is the general perception of well-being, assumed to be strictly related to patient's satisfaction and quality of life $[39,40]$. It contains 18 items and the response to each question is based on a five Likert scale ranging from a large deterioration to a large improvement in health status. 
Citation: Di Mattei VE, Pagani Bagliacca E, Ambrosi A, Lanfranchi L, Baruffaldi Preis F, et al. (2015) The Impact of Cosmetic Plastic Surgery on Body Image and Psychological Well-Being: A Preliminary Study. Int J Psychol Behav Anal 1: 103. doi: http://dx.doi.org/10.15344/2455-3867/2015/103

Page 3 of 6

\section{Statistical analysis}

To verify the seriousness relating to body image affected the postoperative satisfaction, a non-parametric Spearman's correlation coefficents was performed.

The impact of aesthetic plastic surgery on body image and its pathologies was studied through a repeated measures analysis of variance. To investigate the possible relationship between GSI, PGWB-S and surgery types, a three way ANOVA was performed. P-values were computed by means of permutations to avoid any distributional assumptions or asymptotic approximations. P-values < 0.05 were considered significant.

All analyses were performed in R environment 3.0.

\section{Results and Discussion}

\section{Results}

The first aim of this study was to assess the role of uneasiness relating to body image in conditioning the levels of post-operative satisfaction and the benefits perceived by patients.

The Global Severity Index (GSI) was considered for the assessment of Body Image and its pathologies while the overall score of the Glasgow Benefit Inventory (GBI) was used for the assessment of post-operative satisfaction and benefits perceived. On the basis of the BUT scores, in the pre-operative stage (GSI $\geq 1.2$ ), 35 people (corresponding to $41.2 \%$ of the overall sample, $\mathrm{N}=85$, who had completed the questionnaires relating to satisfaction in the postoperative stage) presented an alteration of the representation of the Body Image (Body Image Disorder); in the post-operative stage, instead, 48 patients show a GSI $<1.2$, corresponding to the $56.5 \%$ of the sample $(\mathrm{N}=85)$. The difference between means of the two groups was statistically significant: $\mathrm{p}<0.001$.

To verify the seriousness relating to body image affected the postoperative satisfaction, a non parametric Spearman's correlation coefficient was performed. Figure 1 shows a correlation $\left(r_{s}=-.913\right.$, $\mathrm{p}<.001)$ indicating that the existence of Body Image Disorder (clinically significant uneasiness relating to body image) in the preoperative stage affected post-operative satisfaction (total change in health status perceived) of the patient.

The data, moreover, show that post-operative satisfaction was conditioned by the level of severity of the uneasiness relating to body image which the patients present in the pre-operative stage: the greater the severity, the less the post-operative satisfaction.

The second aim of this research was to study the impact of aesthetic plastic surgery on body image and its pathologies through the analysis of the differences between the pre-operative $\left(\mathrm{t}_{0}\right)$ and post-operative $\left(t_{1}\right)$ stages. A three ways ANOVA with interaction was carried out to test the hypothesis proposed and assess whether there are significant differences between uneasiness relating to body image at $t_{0}$ and that relating to body image at $t_{1}$ (one year after the operation). The GSI index was also considered in this case. Moreover, these results show no evidence of effect related to the type of operations $(\mathrm{p}=.884)$ and of interaction $(\mathrm{p}=.759)$. Figure 2 show the effect statistically significant $(\mathrm{p}<.001)$ represented by the differences $\left(\Delta=\mathrm{GSI} \mathrm{t}_{1}-\mathrm{GSI} \mathrm{t}_{0}\right)$ as function of GSI at $\mathrm{t}_{0}$.

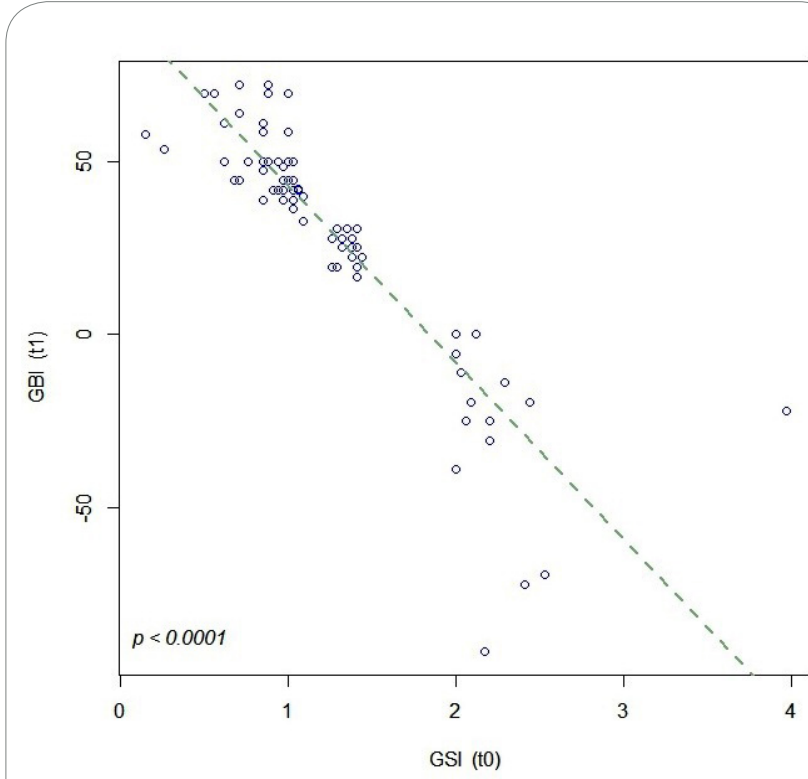

Figure 1: Relationship between GSI $\mathrm{t}_{0}$ and GBI $\mathrm{t}_{1}$. Spearman's correlation coefficient $=-.913$.

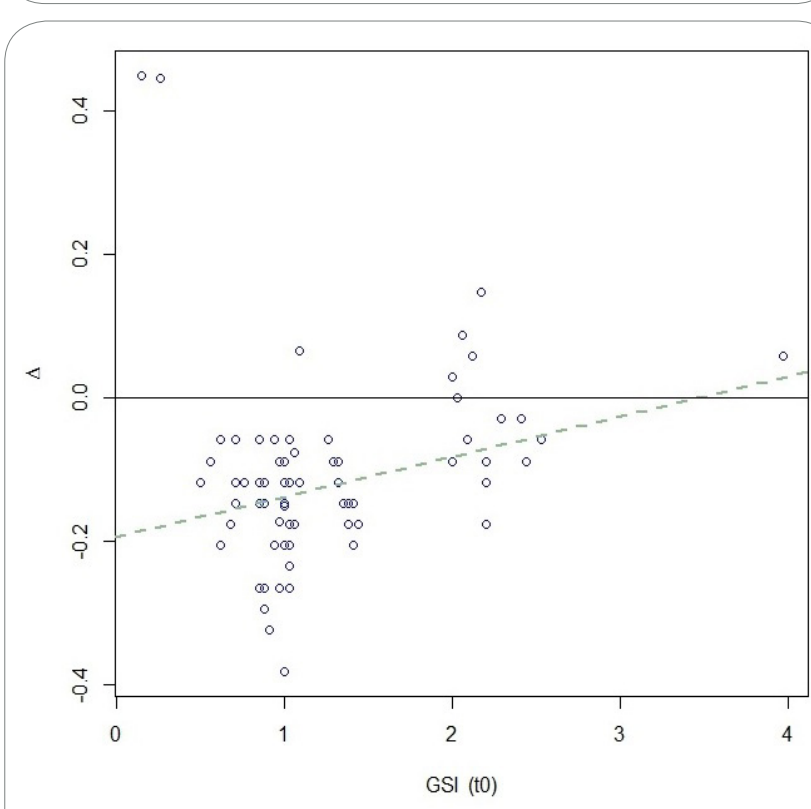

Figure 2: Relationship between the severity of body uneasiness variation $(\Delta)$ as function of GSI at $t_{0}$.

The results illustrated to this point highlight the positive impact of plastic surgery on body image; nevertheless, the improvement in uneasiness with the body image does not depend on the specific type of operation but on the severity index of body image dissatisfaction.

Moreover, the data show that the patients with clinically non significant uneasiness related to body image $(\mathrm{GSI}<1.2)$ at $\mathrm{t}_{0}$ remained the same at the follow-up $\left(t_{1}\right)$ just as all those who presented clinically significant uneasiness related to body image (Body Image Disorder) at $\mathrm{t}_{0}$ presented a clinically significant GSI $(\mathrm{GSI} \geq 1.2)$ also at $\mathrm{t}_{1}$.

The last aim of this research was to study the impact of resorting to aesthetic plasticsurgeryoperations on thestate of well-being/uneasiness 
Citation: Di Mattei VE, Pagani Bagliacca E, Ambrosi A, Lanfranchi L, Baruffaldi Preis F, et al. (2015) The Impact of Cosmetic Plastic Surgery on Body Image and Psychological Well-Being: A Preliminary Study. Int J Psychol Behav Anal 1: 103. doi: http://dx.doi.org/10.15344/2455-3867/2015/103

linked to the emotional and affective sphere (psychological wellbeing) through the analysis of the differences between the pre $\left(t_{0}\right)$ and postoperative $\left(\mathrm{t}_{1}\right)$ stages.

A three ways ANOVA was made to assess the hypothesis proposed and whether there were significant differences between the psychological well-being at $t_{0}$ that at $t_{1}$. To this aim the overall score of the Psychological General Well-Being Index-Short Version (PGWB-S) was used. The results highlight the positive impact of plastic surgery on the state of well-being/uneasiness (psychological well-being; $\mathrm{p}<.001)$. The data, moreover, show no evidence of effect related to the type of operations $(\mathrm{p}=.939)$ and of interaction $(\mathrm{p}=.883)$.

\section{Discussion}

The results obtained from the first part of the study show the importance of differentiating between slight dissatisfaction with one's appearance, which does not reach pathological levels, and the excessive concern, which causes a clinically significant uneasiness within the individual [10]; they also show that the existence of the Body Image Disorder affects the outcome of the intervention [1214]. Lastly, they stress the fact that the post-operative satisfaction of patients depends on the severity of GSI: the greater the severity of the uneasiness in relation to body image in the pre-operative stage, the less the post-operative satisfaction.

The studies conducted assessed the impact of blepharoplasty, rhytidectomy, and breast augmentation/reduction operations on body image but the relationship between body image and other very common operations such as rhinoplasty, abdominoplasty and liposuction needs to be clarified [12]. Empirical research [12] has mainly assessed only the impact of plastic surgery on body dissatisfaction, which, as indicated above, is not, in itself, a sufficiently valid and specific index of Body Image Disorder [9].

With respect to the assessment of the impact of aesthetic plastic surgery on body image and its pathologies, in line with the literature, the results show the positive impact of plastic surgery on body image [41-44] even for the most common operations not studied to date [12]. Nevertheless, the improvement in uneasiness relating to body image depends (there is interaction) on the severity of GSI; while it is true that the main objective of any type of aesthetic operation must be the change in body image [28], it is equally true that (despite the improvement in the uneasiness relating to body image) all those with a Body Image Disorder in the pre-operative stage continue to show it again (GSI $\geq 1.2)$ even at a distance of 12 months from the operation. These data are consistent with the literature which states that, in those with Body Image Disorder, the aesthetic plastic surgery operation is of little use or even counterproductive as it does not substantially modify their alterations of body representation $[18,45-47]$

Despite the lack of homogeneity in the results [12], it was shown in international literature that an improvement in psychological wellbeing follows a positive change in the physical aspect [26,27]. From this preamble, the last objective of this research was the assessment of the impact of aesthetic plastic surgery operations on the state of well-being/uneasiness linked to the emotional and affective sphere (psychological well-being) through the analysis of the differences between the pre $\left(\mathrm{t}_{0}\right)$ and postoperative $\left(\mathrm{t}_{1}\right)$ stages.

The results only support the main effect of the operation; in other words, the positive impact of the plastic surgery on the state of well-being/uneasiness linked to the emotional and affective sphere (psychological well-being) is highlighted. These results are in line with the other studies, which have individually assessed some of the dimensions of psychological well-being recording a reduction in depression, anxiety and an improvement in the state of health [4856]. Since the results are not homogenous and, in some researches [12,57-59], the patients continued to feel uneasiness linked to the emotional and affective sphere in the post-operative stage, the aesthetic correction procedure lead to positive psychological benefits in most patients.

\section{Conclusions}

To summarize, the overview of the results highlights that people requesting an aesthetic plastic surgery operation are moved by the desire to improve the parts of the body that cause them uneasiness $[2,41]$, irrespective of the type of operation they undergo; the postoperative satisfaction of patients and the change in their health is affected by the existence of clinically significant uneasiness relating to body image in the pre-operative stage and depends on how serious it is: the greater the degree of uneasiness in the pre-operative stage, the less the post-operative satisfaction. The operation has a positive impact on both the state of uneasiness linked to the emotional and affective sphere and uneasiness relating to body image but, in the latter case, improvement of the uneasiness depends on the degree of GSI; people with Body Image Disorder in the pre-operative stage continue to present it even at a distance of 12 months from the operation.

The present study is one among the few that investigates whether plastic surgery has an effect on an individual's body image and psychological well-being.

It is a preliminary study and it presents some methodological limitations especially regarding a reduced sample size, a not comparing result of the patient group with an age-matched control group but with population norms, andthe use of self-administered questionnaires. The questionnaire GBI used in this study provides an index of the patient benefit, a concept strictly related to the satisfaction but not interchangeable. Nowadays, there isn't a global index of satisfaction for postoperative plastic surgery. Another potential limit concerns the lack of a formal clinical diagnosis. The study mostly used the BUT which, although widely used for the purpose of Body Image Disorder screening in a wide spectrum of scientifically based research, does not diagnose specific disorders which are included under the conceptual category of 'Body Image Disorders', like Body Dysmorphic Disorder, by the literature. As a preliminary study, we deliberately chose together with the plastic surgeons, to limit our study to underline possible problematic issues on body image, explicitly avoiding diagnosis. Nevertheless, our data suggests that even careful assessment of Body Image issues in the stage before the operation may operation may enable identification of people who will be dissatisfied with the outcome of the operation, with reliable margins of probability. For future advances in our research, we are planning to introduce a diagnostic tool for Body Dysmorphic Disorder.

The importance of the cooperation and integration of the clinical psychologist into both the medical team and the field of research in relation to the well-being of the patient can be easily demonstrated from the results of this study. Close cooperation between psychologists and plastic surgeons is desirable, as has already been demonstrated for some time in the United States, where the patients who are candidates 
Citation: Di Mattei VE, Pagani Bagliacca E, Ambrosi A, Lanfranchi L, Baruffaldi Preis F, et al. (2015) The Impact of Cosmetic Plastic Surgery on Body Image and Psychological Well-Being: A Preliminary Study. Int J Psychol Behav Anal 1: 103. doi: http://dx.doi.org/10.15344/2455-3867/2015/103

Page 5 of 6

for a plastic surgery operation normally undergo a clinical assessment by mental health professionals [36].

\section{Competing Interests}

The author(s) declare that they have no competing interests.

\section{Author Contributions}

V.E. Di Mattei developed the study concept; all authors contributed to the study design.

Testing and data collection were performed by E. Pagani Bagliacca.

A. Ambrosi and E. Pagani Bagliacca performed the data analysis.

E. Pagani Bagliacca and V.E. Di Mattei drafted the manuscript.

L. Lanfranchi, F. Baruffaldi Preis and L. Sarno provided clinical supervisions and critical revisions.

All authors approved the final version of the manuscript for submission.

\section{Acknowledgements}

The authors would like to thank all the patients who took part in this study.

\section{References}

1. American Society for Aesthetic Plastic Surgery, Cosmetic Surgery Nationa Data Bank: 2012 statistics. New York.

2. Henderson-King D, Henderson-King E (2005) Acceptance of cosmetic surgery: scale development and validation. Body Image 2: 137-149.

3. Sarwer DB, Pertschuk MJ, Wadden TA, Whitaker LA (1998) Psychologica investigations of cosmetic surgery patients: A look back and a look ahead. Plast Reconstr Surg 101: 1136-1142.

4. Sarwer DB, Grossbart TA, Didie ER (2002) Beauty and society. In: Kaminer MS, Dover JS, Arndt A, eds. Atlas of cosmetic surgery. Philadelphia: Saunders: $48-59$

5. Sarwer DB, Didie ER (2002) Body image in cosmetic surgical and dermatological practice. In: Castle DJ, Phillips KA, eds. Disorders of Body Image. Hampshire, United Kingdom: Wrightson Biomedical: 37-53.

6. Allamani A, Allegranzi P, Dei M, Rossekki M (1990) Immagine Corporea: dimensioni e misure. Una ricerca clinica. Archivio di Psicolologia Neurologia e Psichiatria 2: 171-195.

7. Pope H, Philips K, Olivardia R. (2002) The adonis complex: how to identify, treat and prevent body obsession in men and boys. New York NY: Touchstone.

8. Rodin J, Silberstein L, Striegel-Moore R (1985) Women and weight: A normative discontent. In: Sondregger TB, eds. Psychology and gender. Lincoln: University of Nebraska Press: 267-307.

9. Cash TF. (2002) A "negative body image": Evaluating epidemiologica evidence. In: Cash TF, Pruzinsky T, eds. Body image: a handbook of theory, research, and clinical practice. New York NY: Guilford Press: 269-276.

10. Sarwer DB, Wadden TA, Pertschuk MJ, Whitaker LA (1998) Body image dissatisfaction and body dysmorphic disorder in 100 cosmetic surgery patients. Plast Reconstr Surg 101: 1644-1649.

11. Rosen J (2004) Obesity and body image. In: Fairburn C, Brownell K, eds Eating disorders and obesity: a comprehensive handbook. New York NY: The Guilford Press; 2002: 399-402.

12. Sarwer DB, Crerand CE (2004) Body image and cosmetic medical treatments. Body Image 1: 99-111.

13. Castle DJ, Honigman RJ, Phillips KA (2002) Does cosmetic surgery improve psychosocial well-being? Med J Aust 176: 601-604.

14. Honigman RJ, Phillips KA, Castle DJ. (2004) A review of psychosocial outcomes for patients seeking cosmetic surgery. Plast Reconstr Surg 113: 1229-1237.

Int J Psychol Behav Anal

ISSN: 2455-3867
15. Alsarraf R (2000) Outcomes research in facial plastic surgery: A review and new directions. Aesthetic Plast Surg 24: 192-197.

16. Alsarraf R, Larrabee WF, Anderson S, Murakami CS, Johnson CM (2001) Measuring cosmetic facial plastic surgery outcomes. Arch Facial Plast Surg 3:198-201.

17. Most SP, Alsarraf R, Larrabee WF Jr (2002) Outcomes of facial cosmetic procedures. Facial Plast Surg 18: 119-124.

18. Veale D (2000) Outcome of cosmetic surgery and "DYS" surgery in patients with body dysmorphic disorder. Psychiaticr Bullentin 24: 228-221.

19. Didie ER, Sarwer DB (2003) Factors which influence the decision to undergo cosmetic breast augmentation surgery. J Womens Health (Larchmt) 12: 241-253.

20. Pertschuk MJ, Sarwer DB, Wadden TA, Whitaker LA (1998) Body image dissatisfaction in male cosmetic surgery patients. Aesthetic Plast Surg 22: 20-24.

21. von Soest T, Kvalem IL, Skolleborg KC, Roald HE (2006) Psychosocial factors predicting the motivation to undergo cosmetic surgery. Plast Reconstr Surg 117: 51-62.

22. von Soest T, Kvalem IL, Roald HE, Skolleborg KC (2009) The effects of cosmetic surgery on body image, self-esteem, and psychological problems. J Plast Reconstr Aesthet Surg 62: 1238-1244.

23. von Soest T, Kvalem IL, Skolleborg KC, Roald HE (2001) Psychosocial changes after cosmetic surgery: a 5-year follow-up study. Plast Reconstr Surg 128: 765-772.

24. Cingi C, Songu M, Bal C (2011) Outcomes research in rhinoplasty: Body image and quality of life. Am J Rhinol Allergy 25: 263-267.

25. de Brito MJ, Nahas FX, Barbosa MV, Dini GM, Kimura AK, et al. (2010) Abdominoplasty and its effect on body image, self-esteem, and mental health. Ann Plast Surg 65: 5-10.

26. Grossbart TA, Sarwer DB (1999) Cosmetic surgery: Surgical tools-Psychosocial goals. Semin Cutan Med Surg 18:101-111.

27. Pruzinsky T, Edgerton MT. (1990) Body-image change in cosmetic plastic surgery. In: Cash TF, Pruzinsky T, eds. Body Images: Development, deviance, and changes. New York NY: Guilford: 217-236.

28. Pruzinsky T (1993) Psychological factors in cosmetic plastic surgery: Recent developments in patient care. Plastic Surgical Nursing 13: 64-69.

29. Molinari E, Riva G (2004) Psicologia clinica dell'obesità. Bollati Boringhieri.

30. Cash TF (1990) The psychology of physical appearance: aesthetics, attributes and images. In: Cash TF, Pruzinsky T eds. Body images: development, deviance, and change. New York: Guildford Press.

31. Allen A, Hollander E (2000) Body dysmorphic disorder. Psychiatr Clin North Am 23: 617-28.

32. Stice $E$ (2002) Risk and maintenance factors for eating pathology: A metaanalytic review. Psychol Bull 128: 825-848

33. Cuzzolaro M, Vetrone G, Marano G, Battacchi M (2000) Body uneasiness test (BUT). In: Conti L, eds. Repertorio delle scale di valutazione in psichiatria. Firenze: SEE: 1759-1761.

34. Cuzzolaro M, Vetrone G, Marano G, Garfinkel PE (2006) The body uneasiness test (BUT): Development and validation of a new body image assessment scale. Eat Weight Disord 11: 1-13.

35. Marano G, Cuzzolaro M, Vetrone G, Garfinkel PE, Temperilli F, et al. (2007) Validating the body uneasiness test (BUT) in obese patients. Eat Weight Disord 12: 70-82.

36. Pollice R, Bianchini V, Giuliani M, Zoccali G, Tomassini A, et al. (2009) Early diagnosis of Dysmorphophobia and other Dysmorphic Disorders: a possible operative model. Rivista Clinica Terapeutica 160: 5-10.

37. Grossi E, Groth N, Mosconi P, Cerutti R, Pace F, et al. (2006) Development and validation of the short version of the Psychological General Well-Being Index (PGWB-S). Health Qual Life Outcomes 4: 88-96. 
Citation: Di Mattei VE, Pagani Bagliacca E, Ambrosi A, Lanfranchi L, Baruffaldi Preis F, et al. (2015) The Impact of Cosmetic Plastic Surgery on Body Image and Psychological Well-Being: A Preliminary Study. Int J Psychol Behav Anal 1: 103. doi: http://dx.doi.org/10.15344/2455-3867/2015/103

38. Robinson K, Gatehouse S, Browning GG (1996) Measuring patient benefit from otorhinolaryngological surgery and therapy. Ann Otol Rhinol Laryngol 105: 415-422.

39. Songu M, Kutlu A (2014) Health-related quality of life outcome of children with prominent ears after otoplasty. Eur Arch Otorhinolaryngol 271: 1829 1832

40. Hao W, Chorney JM, Bezuhly M, Wilson K, Hong P (2013) Analysis of health-related quality-of-life outcomes and their predictive factors in pediatric patients who undergo otoplasty. Plast Reconstr Surg 132: 811817.

41. Sarwer DB, Wadden TA, Whitaker LA (2002) An investigation of changes in body image following cosmetic surgery. Plast Reconstr Surg 109: 363-369.

42. Bolton MA, Pruzinsky T, Cash TF, Persing JA (2003) Measuring outcomes in plastic surgery: Body image and quality of life in abdominoplasty patients. Plast Reconstr Surg 112: 619-625.

43. Cash TF, Duel LA, Perkins LL (2002) Women's psychosocial outcomes of breast augmentation with silicone gel-filled implants: A 2-year prospective study. Plast Reconstr Surg 109: 2112-2121.

44. Sarwer DB, Infield AL, Baker JL, Casas LA, Glat PM, et al. (2008) Two-year results of a prospective, multi-site investigation of patient satisfaction and psychosocial status following cosmetic surgery. Aesthet Surg J 28: 245250.

45. Phillips KA, Hollander E, Rasmussen SA, Aronowitz BR, DeCaria C, et al (1997) A severity rating scale for Body Dysmorphic Disorder: Development reliability and validity of a modified version of the Yale-Brown Obsessive Compulsive Scale. Psychopharmacol Bull 33: 17-22.

46. Veale D, Boocock A, Gournay K, Dryden W, Shah F, et al. (1996) Body dysmorphic disorder: A survey of fifty cases. Br J Psychiatry 169: 196-201.

47. Bellino S, Paradiso E, Zizza M, (2004) II disturbo da dismorfismo corporeo: revisione critica della letteratura. Italian Journal of Psychopatology 10: 237 253

48. Webb WL Jr, Slaughter R, Meyer E, Edgerton M (1965) Mechanisms of psychosocial adjustment in patients seeking "face-lift" operation. Psychosom Med 27: 183-192.

49. Goin MK, Goin JM, Gianini MH (1977) The psychic consequences of a reduction mammaplasty. Plast Reconstr Surg 59: 530-534.

50. Ohlsen L, Ponten B, Hambert G (1978) Augmentation mammaplasty: A surgical and psychiatric evaluation of the results. Ann Plast Surg 2: 42-45.

51. Robin AA, Copas JB, Jack AB, Kaeser AC, Thomas PJ (1988) Reshaping the psyche: The concurrent improvement in appearance and mental state after rhinoplasty. Br J Psychiatry 152: 539-543.

52. Rankin M, Borah GL, Perry AW, Wey PD (1998) Quality of life outcomes after cosmetic surgery. Plast Reconstr Surg 102: 2139-2145.

53. Klassen A, Fitzpatrick R, Jenkinson C, Goodacre T (1996) Should breast reduction surgery be rationed? A comparison of the health status of patients before and after treatment: Postal questionnaire survey. BMJ 313: 454-457.

54. Schnur PL, Schnur DP, Petty PM, Hanson TJ. Weaver AL (1997) Reduction mammaplasty: An outcome study. Plast Reconstr Surg 100: 875-883.

55. Ercolani M, Baldaro B, Rossi N, Trombini G (1999) Five-year follow-up of cosmetic rhinoplasty. Journal of Psychosomatic Research 47: 283-286.

56. Chahraoui K, Danino A, Benony H, Frachebois C, Clerc AS, et al. (2006) Anxiety and subjective quality of life preoperatively and 4 months after reduction mammaplasty. J Psychosom Res 61:801-806.

57. Edgerton MT, Jacobson WE, Meyer E (1960) Surgical-psychiatric study of patients seeking plastic (cosmetic) surgery: 98 consecutive patients with minimal deformity. Br J Plast Surg 13: 136-145.

58. Wright MR, Wright WK (1975) A psychological study of patients undergoing cosmetic surgery. Arch Otolaryngol 101: 145-151.

59. Hollyman JA, Lacey JH, Whitfield PJ, Wilson JS (1986) Surgery for the psyche: A longitudinal study of women undergoing reduction mammoplasty. Br J Plast Surg 39: 222-224. 